\title{
National Cultural Dimensions, Emerging Market Characteristics and the Subsidiary's Willingness to Transfer Marketing Knowledge to MNE HQs
}

Authors:

1. Ahmad Arslan, D.Sc. (Econ), Senior Lecturer (International Business), Business School, Edge Hill University, Ormskirk, Lancashire, United Kingdom

Email: arslana@edgehill.ac.uk

2. Tiina Tuulikki Leposky, M.Sc (Econ), Doctoral Student, Department of Marketing, University of Vaasa, Finland Email: tiina.leposky@uva.fi

3. Minnie Kontkanen, D.Sc. (Econ), University Lecturer, Department of Marketing, University of Vaasa, Finland Email: minnie.kontkanen@uva.fi

This is an Accepted Manuscript of an article published online by Taylor \& Francis in JOURNAL OF TRANSNATIONAL MANAGEMENT on $21^{\text {ST }}$ July, 2016, available online at

http://www.tandfonline.com/doi/abs/10.1080/15475778.2016.1192917

Please cite this paper as:

Arslan, A., Leposky, T. T., \& Kontkanen, M. (2016). "National Cultural Dimensions, Emerging Market Characteristics and the Subsidiary's Willingness to Transfer Marketing Knowledge to MNE HQs" Journal of Transnational Management, 21(3), 162-179. 


\title{
National Cultural Dimensions, Emerging Market Characteristics and the Subsidiary's Willingness to Transfer Marketing Knowledge to MNE HQs
}

\begin{abstract}
Subsidiaries in emerging markets (EMs) are a valuable source of knowledge for multinational enterprises (MNEs). Accessing the vast potential of these markets is increasingly becoming a priority for businesses from developed countries, but success in the markets requires understanding marketing in the emerging market context, which may differ considerably from the accepted truths of the traditional Western approaches. This paper seeks to improve understanding of the emerging market contextual factors, which influence the willingness to transfer marketing knowledge from emerging market subsidiaries to headquarters of multinational companies. Using the GLOBE cultural framework, this paper proposes that the relationships between power distance, uncertainty avoidance, in-group collectivism, performance orientation, and future orientation with knowledge transfer willingness are made moderated by the EM characteristics of shortage of resources, strong socio-political governance, inadequate infrastructures, country of origin -effect and turbulence of the environment. A conceptual framework and propositions for future study are presented accordingly.
\end{abstract}

Keywords: Emerging markets; GLOBE cultural framework; knowledge transfer; Subsidiary 


\section{INTRODUCTION}

Subsidiaries are an essential part of the global value chain of multinational enterprises (MNEs) and therefore headquarters (HQ) need their input for both strategic and operational matters (Goerzen and Beamish, 2003; Mudambi et al., 2014). Consequently, relationships between HQs and foreign subsidiaries have been referred to as among the most crucial issues in MNE management (Hoenen and Kostova, 2014). Previous studies have also indicated that the longterm prosperity of an organization is linked to the sharing of intangible assets like knowledge (e.g. Cantwell and Mudambi, 2005). After all, in isolation a unit, either the HQ or an individual subsidiary, cannot possess sufficient knowledge to compete effectively in global markets. The integration and blending of knowledge from various external and internal networks is necessary to gain a competitive advantage on a global level (Lane et al., 2001: Mudambi et al., 2014; Vance et al., 2014).

Earlier IB research has found that acquiring knowledge from external sources can be a difficult and costly process for MNEs, especially in emerging markets (EMs), where the tacit nature of informal institutions (e.g. Arslan, 2012; Khanna and Palepu, 2013) can make learning very difficult. As such, MNEs are increasingly viewing EMs not only as a source of rapid growth and expansion, but also as a learning opportunity to increase organizational knowledge based on their unique conditions (e.g. Zhang et al., 2010; Xu and Meyer, 2013; Mudambi et al., 2014). In this regard, established EM subsidiaries can play a pivotal role for MNEs' global strategy by acquiring local information and transferring it back to their HQs (Ambos et al., 2006; Pearce and Papanastassiou, 2006; Monteiro et al., 2008). The willingness of EM subsidiaries to transfer knowledge is linked with their incorporation in organizational routines and practices at a global or regional level (Mudambi et al., 2014). 
A review of past studies reveals that IB literature lacks studies addressing knowledge transfer from EM subsidiaries to MNEs' HQ (e.g. Monteiro et al., 2008; Rabbiosi and Santangelo, 2013), although EM subsidiaries increasingly hold a key role in the global strategy of MNEs. IB scholars have also noted that few attempts have been made to explain either theoretically or empirically the reasons for success or failure of knowledge flows from subsidiaries located in EMs (e.g. Monteiro et al., 2008; Yang et al., 2015). Therefore, it is important for IB researchers to enhance understanding in this area by specifically addressing this topic. A further impetus is provided as the failure of some large MNEs in a certain geographical region has been linked to a lack of appreciation of EM subsidiaries' capacity for knowledge transfer, thus perpetuating a Western-centric approach to subsidiary management (Paik and Choi, 2005).

This paper represent an effort to strengthen the understanding of competitive sources of knowledge from host countries for MNE HQs, an aspect which IB scholars have increasingly urged to be analyzed in-depth (e.g. Vance et al., 2009, 2014). We contribute to IB literature by being one of the first studies (at least to our knowledge) to address knowledge transfer of a specific organizational function i.e. marketing from EM subsidiaries to MNEs' HQ in the context of national cultural dimensions, as well as EM specific characteristics like sociomarket heterogeneity, socio-political governance, unbranded competition, chronic shortage of resources, and inadequate infrastructures. Moreover, the conceptual framework developed in this paper sets a basis for further investigation on analyzing complex overlap between cultural dimensions and EM specific characteristics for MNE strategies in EMs.

\section{THEORETICAL BACKGROUND}

Marketing strategies and functions in EMs differ significantly from developed economies because of their network structures and the dynamics of actors involved in marketing (Shapiro 
and Varian, 2013; Qiu, 2014). Moreover, the importance of marketing as a function as well as a part of the organizational strategy is signified by the fact that it is directly related to boundary spanning links between customers and other organizational units within the whole MNE (Schlegelmilch and Chini, 2003; Qiu, 2015). It is important to note that marketing functions located in EM subsidiaries typically create knowledge and strategies in their own socio-cultural context. However, this knowledge can also have potentially useful implications for the global strategies of the MNE, as well as for other EM subsidiaries, where the MNE may not have a direct presence or lacks significant local knowledge.

Knowledge management and transfer literature has referred to the importance of national/local culture in relation to the willingness of an organizational entity to share and transfer knowledge (e.g. Holden, 2002; Javidan et al., 2006; Vance et al., 2014). We argue that EM subsidiary's context (including cultural dimensions and EM characteristics) can play an important role to determine the willingness of focal subsidiary to transfer marketing knowledge produced there. A review of previous IB studies reveals that so far no study (at least to our knowledge) has specifically addressed national cultural dimensions in relation to willingness of an EM subsidiary to transfer the function specific knowledge (marketing in the case of this paper) to HQs of MNEs. Moreover, previous studies on knowledge transfer from subsidiaries to HQs mostly addressed knowledge at general level (e.g. Ambos et al., 2006; Rabbiosi, 2011; Rabbiosi and Santangelo, 2013); thereby ignoring specific characteristic of different organizational functions. We acknowledge these gaps in literature, and aim to address them in our paper by concentrating on a key organizational function of marketing in relation to national cultural dimensions as well as EM specific characteristics. 
The need to study EMs in their own context has been deemed important due to the fact that their unique characteristics offer challenges that may not be overcome using methods and thought patterns created in the context of developed countries (Ghauri et al., 2015). Sheth (2011) identified certain characteristics unique to the EM context namely market heterogeneity, socio-political governance, unbranded competition, chronic shortage of resources, and inadequate infrastructures. We refer to these characteristics in this paper to explore how they may influence the cultural disposition to transfer knowledge, resulting in differences in what might be expected as knowledge transfer willingness in Western context.

Market heterogeneity refers to the vast differences in the market segments in EMs. Marketing for the base of the pyramid is very different from catering to the luxury goods market, both of which are frequently found in EMs. It makes forecasting difficult and segmentation more dynamic (Qian \& Soopramnien, 2015). This market heterogeneity is closely linked with the rapidly changing environmental conditions in EMs (Wang et al., 2014; Ghauri et al., 2015). Hence, we also refer to turbulence of environment in our discussion for this paper. Sociopolitical governance is a characteristic of the strong institutions typically found in EMs. These may be political monoliths, religious bodies or financial monopolies, to name but a few examples of institutions that generally have a power position stronger than what is expected in Western countries (Ghauri et al., 2015).

Competition in EMs is often local, small-scale and unbranded (Sheth, 2011). This is partly due to the lack of infrastructures enabling larger scale production, but infrastructures also have a wider societal impact, as their weakness makes companies protective of intellectual capital when legal protection is low (Yang et al., 2014). Therefore, country of origin effect for the western MNEs can be significant in emerging markets in terms of gaining market share (Wei 
et al., 2014). Finally, shortage of resources means that many EMs frequently lack such essentials as water and power (Sheth, 2011), and are also in need of expertise and soft skills in areas like marketing and HR.

Culture is a key construct in IB research that has been conceptualized and operationalized in a variety of ways. The cultural characteristics of the knowledge source have been highlighted as an important enabler or inhibitor (e.g. Javidan et al., 2005; Minbaeva et al., 2014) for knowledge transfer across national boundaries. In this context, Welsham (2001) presents a convincing argument that due to the differences in the concept of knowledge itself, knowledge transfer depends heavily on culture. We further argue that in the case of EM subsidiaries and culturally dependent organizational functions like marketing, there is an added importance to analyzing in-depth the different dimensions and their influences on willingness of the subsidiary to transfer that knowledge.

IB researchers have used different cultural dimensions in their analysis based on the objectives and scope of their studies. However, the main frameworks used include Hofstede (e.g. 1980, 2001), Schwartz (1994), Trompenaars and Hampden-Turner (1998), and House et al. (2004). Despite the extensive use of Hofstede's work on cultural dimensions in IB research, the model has received criticism in recent years (e.g. Ronen and Shenkar, 2013; Ambos and Hakansson, 2014). The GLOBE project cultural dimensions, however, are more objective and relevant in addressing cultural influences on the willingness of a subsidiary to transfer knowledge to HQs. The cultural dimensions of the GLOBE project include: power distance; uncertainty avoidance; collectivism; in-group collectivism; humane orientation; performance orientation; assertiveness; gender egalitarianism; and future orientation (House et al., 2004). The GLOBE study represents the results of a quantitative database of about 17,000 managers from 951 
organizations in three branches (financial services, food processing, and telecommunications) operating in 62 cultures throughout the world (House et al., 2004: 3). The GLOBE dimensions were chosen because of their research design, the possibility to distinguish between cultural values and practices, and access to more recent data compared to Hofstede. Detailed descriptions of data collection and analysis process and cross-cultural instrument design indicate good validity and reliability.

Previous studies analyzing the role of culture in knowledge transfer have mostly focused on the effect of cultural distance between the units in which knowledge transfer takes place, thus arguing that knowledge transfer is more successful between units which are culturally more similar (see e.g. Holden 2002; Lucas 2006; van Wijk et al., 2008; Nguyen et al., 2012). In addition, findings also support the argument that cultural differences provide great potential for knowledge transfer (see e.g. Sarala and Vaara 2010; Vaara et al., 2012) and some studies have found cultural distance to have insignificant influence (see meta-analysis by Hua Li et al., 2014). Thus, results have been contradictory. However, how the specific cultural characteristics of a sender affect the willingness to transfer knowledge are analyzed with limited scope. Most of such studies explore knowledge transfer between units representing the same national culture (see e.g. Lai and Lee, 2007; Wilkesmann et al., 2009). Therefore, we argue that more systematic analysis of the role of selected cultural characteristic is required; which the current paper aims to perform.

According to Javidan et al. (2006:899), national culture is defined in GLOBE as "values beliefs, norms and behavioral patterns of a national group" and therefore it is considered important to make the distinction between values and practices. Javidan et al. (2006) further argue that this approach is against the conventional belief that cultural values alone represent culture and lead 
to the actual behavior. In addition, it has been acknowledged that two cultures may be associated with different behaviors even though having the same levels of cultural dimension. Thus in GLOBE, cultural dimensions are measured both in terms of practices and values. Practices are measured by "What is" or "What are" in this society and values are expressed in terms of "What Should Be" in this society. (House et al., , 2004:16). Based on the GLOBE findings, cultural practices were associated with societal phenomena like economic health or national competitiveness (Javidan et al., 2006:903), and thus we consider that it is more useful to take into account the practices of culture when considering the interactive effect of culture and emerging market characteristics on knowledge transfer.

We have chosen the following five cultural dimensions based on GLOBE for further analysis: uncertainty avoidance, power distance, in-group collectivism, future orientation and performance orientation. Findings in prior studies utilizing Hofstede's cultural dimensions, indicate the importance of power distance, individualism-collectivism and uncertainty avoidance in knowledge transfer (see e.g. Qin et al., 2008; Chen et al., 2010; Hua Li et al., 2014). In addition, a study by Wilkesmann et al. (2009) utilized the practices of cultural dimensions based on GLOBE in exploring which cultural characteristics in Germany and Hong Kong influence knowledge transfer. Even though it focused on knowledge transfer in intraorganizational level the results support the idea that power distance, performance orientation, in-group collectivism and uncertainty avoidance are the relevant dimensions in analyzing knowledge transfer willingness.

The three dimensions of humane orientation, assertiveness, and gender egalitarianism were not selected, because based on their definitions they do not have obvious relations to the senders willingness to transfer knowledge. Humane orientation dimension defined as "the degree to 
which individuals in organizations or societies encourage and reward individuals for being fair, altruistic, friendly, generous, caring and kind to others" refers to the nature of social relationships (House et al., 2004: 13). Characteristics of relationships between senders and receivers of knowledge have been found important in efficient knowledge transfer (Michailova and Mustaffa, 2012). However, the qualities related to high humane orientation societies i.e. to providing social support to one another and protecting societal members through personal and family relations (Van Emmerik et al., 2010), does not indicate to have an important role in this study context. In a similar way, the definitions of the assertiveness and gender egalitarianism dimensions (see. House et al., 2004) show their relative irrelevance in context of knowledge transfer analysis.

The relevant discussion exploring the relationship between selected cultural dimensions, EM context specific characteristics, and willingness of a subsidiary to transfer marketing knowledge are discussed in the following section.

\section{STUDY PROPOSITIONS}

Power distance is defined as "the degree to which members of an organization or society expect and agree that power should be stratified and concentrated at higher levels of an organization or government' (House et al., 2004:12). Even though the main focus in prior studies exploring the role of culture in knowledge transfer has been on cultural distance, the findings have shown the relevance of power distance dimension in technology transfer (Qin et al., 2008; Chen, et al., 2010; Hua Li et al., 2014). It is therefore reasonable to expect that power distance can influence the willingness to transfer knowledge. Moreover, as there is significant correlation between the GLOBE power distance practices dimension and Hofstede's power distance index (Carl et al., 2004), findings based on Hofstede's power distance dimensions can have similar implications to GLOBE. Previous research has indicated that high power distance 
cultures tend to prevent effective knowledge sharing because there may be less opportunity for constructive discussions between subsidiaries and HQs (Chen et al., 2010). In addition, Wilkesmann et al. (2009) found that in high power distance cultures, knowledge is provided mostly in top down direction and in the bottom up direction only when asked. High power distance has also been referred as a cultural practice which inhibits intrinsic motives for knowledge transfer. Based on this we expect that the willingness to transfer knowledge from subsidiary to HQ is low in high power distance cultures.

However, at the same time EM specific characteristics also influence willingness to transfer knowledge. One of the distinctive characteristics of EMs is a chronic shortage of resources, which has also been linked with innovation. Having to make do with what they have, EM actors are forced to come up with ways to overcome market heterogeneity through inventive new measures (Ernst et al., 2015). Realizing the innovations on ground may, however, require additional resources in for example product development or marketing expertise, which are held at the MNE HQs. Therefore, resource shortage can potentially moderate some negative aspects of power distance, as it can force a subsidiary to transfer knowledge, despite cultural barriers emerging from high power distance.

Furthermore, the prevalence of strong socio-political institutions often means that local firms with a historically strong presence in the market have an advantage in dealing with said institutions and can use their position to block new, foreign companies from the market (Ghauri et al., 2015). Subsidiaries of foreign MNEs can attempt to overcome this by utilizing the status power of a foreign brand and the economic clout of the headquarters. In this context, White et al. (2015) state that EM subsidiaries of MNEs can use competitive organizational capabilities developed from HQ resources to better survive in such conditions. Therefore, these subsidiaries 
need to counter institutional imbalance and challenges of sociopolitical governance, by establishing a mechanism of knowledge transfer to HQs, and seek additional resources in return. Based on this discussion, we propose that

\section{P1: The negative relationship between power distance and willingness to transfer marketing} knowledge to HQs by EM subsidiary is moderated by socio-political governance structures and shortage of resources.

Uncertainty avoidance (UA) is defined as "the extent to which members of an organization or society strive to avoid uncertainty by relying on established social norms, rituals and bureaucratic practices. People in high uncertainty avoidance cultures actively seek to decrease the probability of unpredictable future events that could adversely affect the operation of an organization or society and remedy the success of such adverse effect'” (House et al., 2004:11). Influences of UA specifically on knowledge transfer have not been extensively addressed. Studies by Lucas (2006) and Wilkesmann et al. (2009) represent some of such attempts.

Lucas (2006) argues in his conceptual paper that strong UA creates resistance to change, but weak UA societies are looking for new and better ways to do things, thus increasing the interest in knowledge transfer opportunities. This is supported by Wilkesmann et al. (2009:474) who found that in Germany, where the UA index is much higher than in the comparison group Hong Kong, there was a need for clear responsibilities for example on what knowledge to transfer and how. Germans were also found to be more distrustful to start new projects and initiate transferring their knowledge. In high UA cultures, this may lead to unwillingness to transfer knowledge if there are no clear systems and practices available for knowledge transfer. Therefore, it can be expected that UA is negatively associated with marketing knowledge transferability to MNE HQs. 
However, EMs have the specific characteristic of lack of established infrastructures, whereby subsidiaries need alternate means to achieve their goals. This lack of established infrastructures leads to an environment where corruption is evident (Uhlenbruck et al., 2006) and institutional protection of law uncertain (Khanna and Palepu, 2010). Therefore, actors on the field have to rely on interpersonal networks, where trust has an important role to play (Lai et al., 2014). Therefore the inadequacy of infrastructures typical to EMs can actually negate the impact of uncertainty avoidance, as actors are familiar with dealing through informal networks rather than strictly formalized routines and mechanisms. They may also be less dependent on reporting tools, which may not be common in especially the more rural areas of EMs, and therefore lack of electronic systems may not be an issue. The favorable impact of resources on organizational capabilities has been discussed by many researchers (e.g. Lockett and Wright, 2005; Andersson et al., 2015). Previous literature has mentioned that in EMs business ventures should possess unique capabilities to cope with the complexity arising from lack of established infrastructure and quick changes in industry norms (Zhou et al., 2014). This aspect is closely linked with shortage of local resources in EMs.

EM subsidiaries tend to have a greater need for resources from headquarters, because the pool of recruiting knowledgeable employees is smaller (Contractor et al., 2014). EM subsidiaries also need resource combination of unique local capabilities and HQ resources to outperform their competitors (e.g. Sirmon et al., 2008; Zhou et al., 2014). Therefore, it can be argued that EM subsidiaries would benefit from developing mechanisms for knowledge transfer to HQs despite the cultural attribute to UA, in order to achieve the required competitiveness and profitability. Based on this discussion, we propose that 


\section{P2: The negative relationship between uncertainty avoidance and willingness to transfer marketing knowledge to HQs by an EM subsidiary is moderated by inadequacy of infrastructures and shortage of resources.}

In-group collectivism is defined as "the degree to which individuals express pride, loyalty, and cohesiveness in their organizations or families"' (House et al., 2004: 12). This dimension in terms of practices was found to have a significant and high negative correlation with Hofstede's individualism index, thus representing a similar issue. Previous literature has established that knowledge transfer outside the in-group can be viewed as risky in some cultures (e.g. Chong and Besharati, 2014). In such cultures, people tend to share knowledge primarily within the in-group, while viewing others as a potential threat to their power and rewards (e.g. Chong and Besharati, 2014). Consequently, Wilkesmann et al. (2009) found that in Hong Kong, representing high in-group collectivism, a lot of knowledge was transferred within the in-group such as among peers but less with others. This indicates that motivation to transfer knowledge between out-group members such as subsidiaries to HQs is lower. Moreover, IB literature has established that many EM employees tend not to have strong loyalty towards employers (Kuznetsov et al., 2000). Hence, in-group collectivism can be expected to negatively influence willingness to transfer marketing knowledge.

Knowledge management literature has established that transfer occurs when entities (individuals and organizations) perceive the value of knowledge sharing (Chow and Chan, 2008). This aspect has importance in case of EMs with high in-group collectivism. Moreover, some EMs display an underdeveloped factor market, including shortages of skilled labor (Johnson and Tellis 2008; Sheth 2011). This shortage of skilled labor resources can in turn increase the focal EM subsidiary's dependence on HQs for expatriates to run certain operations. Therefore, resource shortage in EMs can lead to subsidiaries engaging in knowledge transfer 
despite high in-group collectivism because they would value such sharing (Chow and Chan, 2008) due to interest in gaining human and financial resources from HQs. Moreover, as the context of our paper is based on western MNEs' subsidiaries in EMs, it is important to bring a key EM characteristic of country of origin effect in discussion. Western MNEs and western brands tend to have a positive image and strong country of origin effect in EMs (e.g. Godey et al., 2012: Touzani et al., 2015). Therefore, in such cases, despite high in-group collectivism, the EM subsidiary and its employees are expected to feel proud and positive about their association with a known firm. For example, previous researchers have found that despite ingroup collectivism, MNE employees in Middle Eastern countries tend to be more loyal and positive towards knowledge transfer initiatives (e.g. Al-Husan et al., 2014; Barak, 2014). Therefore, in such cases, willingness to transfer marketing knowledge can be achieved despite negative influences of in-group collectivism. Based on this discussion, we propose that

P3: The negative relationship between in-group collectivism and willingness to transfer marketing knowledge to HQs by an EM subsidiary is moderated by country of origin effect and shortage of resources.

Performance orientation is defined as "the degree to which an organization or society encourages and rewards group members for performance improvement and excellence", (House et al., 2004: 13). In high performance oriented cultures rewards are an important source for motivation. This means that without clear rewards and recognition of completed tasks there is no interest in transferring knowledge. In their study, Wilkesmann et al. (2009) found that intrinsic motivation is not important in high performance oriented cultures, but rather the importance of extrinsic incentives is emphasized. 
Previous literature has mentioned that performance orientation focuses on the desired final product or fulfillment of organizational goals (Michaelova and Hutchings, 2006). Hence, some studies have found that performance orientated cultures tend to concentrate on their own goals and success, rather than sharing skills or knowledge with others (Riege, 2005). Therefore it can be expected that in performance oriented cultures, the motivation for knowledge transfer can be lower in an EM subsidiary unless it is associated with some kind of tangible or intangible incentive (Mueller, 2012). In EMs, local firms can gain government-regulated resources, such as subsidies, bank loans, and tax breaks (Khwaja and Mian 2005). For MNE's subsidiaries, such opportunities are limited. However, with a superior marketing capability, firms can identify market trends quickly and market products efficiently (Rindfleisch and Moorman, 2003). Therefore resources from the HQ can generate a competitive advantage in a context of local general shortage of resources, because they are unique and difficult to imitate (Andersson et al., 2015). However, this would also mean that the focal EM subsidiary needs to transfer knowledge to HQs to gain those marketing resources, despite hurdles due to cultural characteristic of performance orientation.

Along with a shortage of resources, another EM aspect that needs to be considered in this context, is the country of origin effect. In many EMs, incentive can be linked to positive image of country of origin of foreign MNEs, as well as shortage of resources in that particular EM. For example, the studies on consumer behavior show that in many EMs consumers prefer imported goods from western companies due to the country of origin effect (Touzani et al., 2015). Western goods are seen as having a prestige value and they symbolize progress and modernity (Üstuner \& Holt, 2010). Combined with an increased need to gain branding expertise and marketing resources from the headquarters, it can be argued that the need for extrinsic incentives can to some measure be mitigated by the prestige value of the foreign brand 
name and associated status of operating under a brand umbrella. Based on this discussion, we propose that

P4: The negative relationship between performance orientation and willingness to transfer marketing knowledge to HQs by an EM subsidiary is moderated by the country of origin effect and shortage of resources.

Future orientation is defined as "the degree to which individuals in organizations or societies engage in future-oriented behaviors such as planning, investing in the future, and delaying individual or collective gratification" (House et al., 2004:12). Cultures which score higher in future orientation tend to have individuals who are more intrinsically motivated than in cultures with past orientation (Ashkanasy et al., 2004:302). Similarly, cultures with low future orientation may be unwilling to be active in preparing plans to realize their goals leading to low willingness to become a sender in knowledge transfer.

In stable environments, the tendency to repeat past behavior and not being able to evaluate plans in terms of anticipated future benefits is specific for low future oriented cultures (Ashkanasy et al., 2004). However, in case of EMs, the situation is rather reversed due to presence of high turbulence in the environment (Sheth, 2011). In EMs such as Brazil, China, and Russia, business environments tend to be highly complex and turbulent, caused mostly by policy ambiguity, government intervention, and institutional transition. This environmental turbulence is a key risk for subsidiaries in EMs, because rapid changes in the external environment may restrict their ability and opportunities to do business effectively (White et al., 2014). Therefore, local firms as well as subsidiaries of foreign MNEs face a dilemma where their firm specific knowledge accumulated under different conditions loses importance with ongoing changes (Newman, 2000). Hence, the need for inter firm collaboration increases in 
such cases (Tan and Peng, 2003). In the case of MNE subsidiaries this means an increased emphasis on being part of the global value chain and network of an MNE (Ghauri and Santangelo, 2012; Wei et al., 2014) and on establishing a mechanism of knowledge transfer to achieve competitiveness and market responsiveness in that context (Wei et al., 2014). Based on the above discussion, we propose that

P5: The negative relationship between weak future orientation and willingness to transfer marketing knowledge to HQs by an EM subsidiary is moderated by high level of turbulence of the environment.

We present a framework based on above mention propositions in Figure 1.

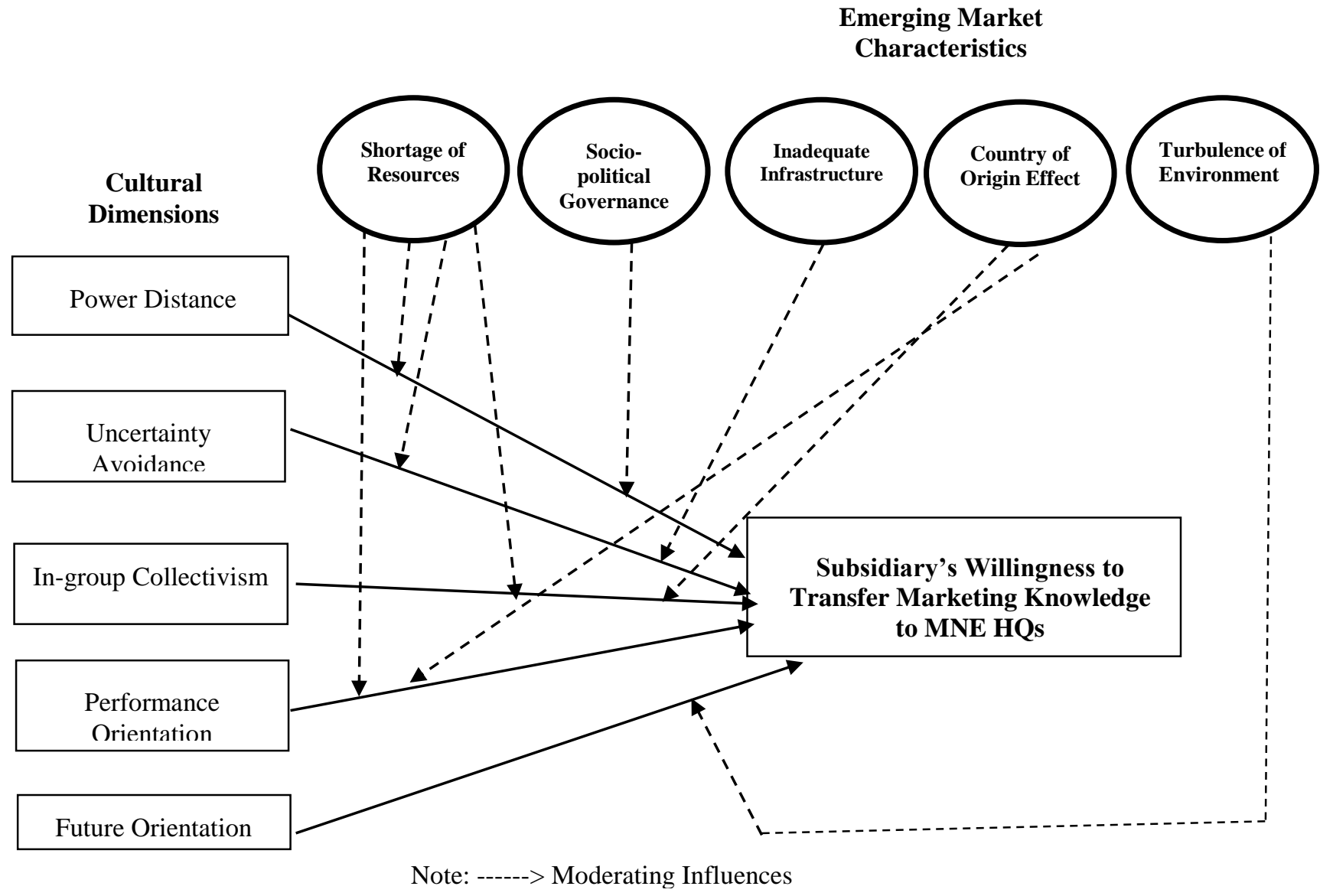

Figure 1: EM characteristics, Cultural Dimensions and Subsidiary's Willingness to Transfer Marketing Knowledge to HQs 


\section{DISCUSSION, IMPLICATIONS AND FUTURE RESEARCH DIRECTIONS}

This paper addresses a relatively little researched topic of marketing knowledge transfer from EM subsidiaries to MNE HQs. The paper enriches IB literature in two ways. Firstly, the paper contributes to knowledge transfer stream in IB literature by specifically concentrating on the organizational function of marketing, rather than a general discussion as offered in many past studies. Secondly, the paper conceptually addresses as well as integrates EM characteristics (Sheth, 2011), while analyzing the influences of national cultural dimensions on marketing knowledge transfer from EM subsidiaries to MNE HQs. The conceptual framework developed in the paper sets a basis for further exploration on this complex interplay between EM characteristics and national cultural dimensions, not only in the context of knowledge transfer, but also other aspects of MNEs' global strategies.

We offer an in-depth conceptual review which leads to the development of five study propositions addressing willingness to transfer marketing knowledge from EM subsidiaries to MNE HQs. We found that due to the complex character inherent in marketing strategies and functions especially in EMs, it is important to include EM characteristics in the discussion of influences of cultural dimensions on knowledge transfer. Hence, we address the EM's turbulence of environment, country of origin, inadequate infrastructure, socio-political governance, and resource shortage in relation to cultural dimensions like power distance, uncertainty avoidance, in-group collectivism, performance orientation and future orientation. The discussion offered in the paper clearly reveals that in EMs, there is a need to understand context specific factors rather than having a simplistic discussion on direct influences of cultural dimensions of (marketing) knowledge transfer. 
The discussion offered in our paper has practical implications for the managerial audience also. Our paper has signified the importance of EM subsidiaries as a potential knowledge source (especially function specific knowledge like marketing) for MNE managers. Therefore, due to increasing importance of EMs for MNEs, the managers can start to appreciate subsidiaries located there for knowledge creation and transfer, rather than treating them as a revenue source and mere recipients of knowledge from HQ. Our study also highlighted some of the complex interrelationships between dimensions of local culture and EM characteristics in relation to their influence on marketing knowledge transfer willingness. Such a discussion can be seen as a stepping stone for broader implications for other aspects of MNE strategies (and especially marketing strategies) in EMs. Therefore, MNE managers should consider EM specific characteristics when analyzing potential influences of culture on the devised strategies, because an understanding based on linear influences of cultural dimensions on MNE strategies can be misleading and potentially harmful.

Our paper also has certain limitations, like any other academic endeavor. Firstly, the study is conceptual in nature, and hence lacks the empirical support for the developed conceptual model and propositions. However, the study offers an important stepping stone in highlighting the importance of EM subsidiaries for marketing knowledge transfer to HQs, and the influences of context specific factors as well as cultural dimensions. Hence, we believe that future studies can continue such analysis forward by testing the developed positions and models in a variety of EM settings. Although a generalized concept of EMs is used in literature, in reality they have huge differences based on the five contextual elements we also used in this paper. Therefore there is a potential to contribute to IB literature for future studies, if they can analyze the difference among various EMs for marketing (and other organizational functions') knowledge transfer willingness. It is also important to mention that cultural factors from 
MNEs' HQ and the cultural differences between HQs and subsidiary (i.e. cultural distance) influence knowledge transferability. However, this aspect was not in the context of the current study, and we only concentrated on the cultural characteristics of the country where subsidiary is located in relation to EM specific characteristics. Future studies can look into this aspect by analyzing cultural characteristics of recipient along with the sender. Moreover, we do not specifically refer to relationship between HQs and subsidiary and importance of subsidiary in MNEs' network, as these factors also have the potential to influence knowledge transfer. However, a key goal of the paper was to signify EM context in relation to knowledge transfer willingness to HQs, and therefore we concentrated on the relevant cultural dimensions and EM specific characteristics in this paper. Future studies have the possibility to extend the framework developed in our paper by incorporating the elements that influence knowledge transferability in line with the goals and context of their studies.

Last, but not least, our paper is focused on marketing knowledge transfer from EM subsidiaries to MNE HQs and other organizational functions are not included in the discussion and analysis. However, our paper signified the importance of performing function specific analysis and discussion in context of knowledge transfer literature, rather than a generalized approach. Therefore, future studies can address other organizational functions like production and operation management, logistics and supply chain and human resource management in context of knowledge transfer to MNE HQs. 


\section{REFERENCES}

AL-Husan, F. B., AL-Hussan, F. B., \& Perkins, S. J. (2014). Multilevel HRM systems and intermediating variables in MNCs: longitudinal case study research in Middle Eastern settings. The International Journal of Human Resource Management, 25(2), 234-251.

Ambos, B., \& Håkanson, L. (2014). The concept of distance in international management research. Journal of International Management, 20(1), 1-7.

Ambos, T. C., Ambos, B., \& Schlegelmilch, B. B. (2006). Learning from foreign subsidiaries: An empirical investigation of headquarters' benefits from reverse knowledge transfers. International Business Review, 15(3), 294-312.

Ambos, T. C., Ambos, B., \& Schlegelmilch, B. B. (2006). Learning from foreign subsidiaries: An empirical investigation of headquarters' benefits from reverse knowledge transfers. International Business Review, 15(3), 294-312.

Andersson, U., Buckley, P. J., \& Dellestrand, H. (2015). In the Right Place at the Right Time!: The Influence of Knowledge Governance Tools on Knowledge Transfer and Utilization in MNEs. Global Strategy Journal, 5(1), 27-47.

Arslan, A. (2012). Impacts of Institutional Pressures and the Strength of Market Supporting Institutions in the Host Country on the Ownership Strategy of Multinational Enterprises: Theoretical Discussion and Propositions. Journal of Management and Governance, 16(1), 107124.

Ashkanasy N., Gupta, V., Mayfield, M.S., \& Trevor-Roberts, E. (2004). Future Orientation. In House, R. et al. (Eds), Culture, Leadership, and Organizations. The GLOBE Study of 62 Societies. (pp. 282-342), Thousand Oaks, CA: Sage.

Barak, M. E. M. (2013). Managing diversity: Toward a globally inclusive workplace. Thousand Oanks, CA: Sage.

Cantwell, J., \& Mudambi, R. (2005). MNE competence-creating subsidiary mandates. Strategic management journal, 26(12), 1109-1128.

Carl, D., Gupta V. \& Javidan M. (2004). Power distance. In House, R. et al. (Eds), Culture, Leadership, and Organizations. The GLOBE Study of 62 Societies. (pp. 513-563), Thousand Oaks, CA: Sage.

Chen, J., Sun, P. Y., \& McQueen, R. J. (2010). The impact of national cultures on structured knowledge transfer. Journal of knowledge management, 14(2), 228-242.

Chong, C. W., \& Besharati, J. (2014). Challenges of knowledge sharing in the petrochemical industry. Knowledge Management \& E-Learning: An International Journal (KM\&EL), 6(2), 171-187. 
Chow, W. S., \& Chan, L. S. (2008). Social network, social trust and shared goals in organizational knowledge sharing. Information \& Management, 45(7), 458-465.

Contractor, F. J., Lahiri, S., Elango, B., \& Kundu, S. K. (2014). Institutional, cultural and industry related determinants of ownership choices in emerging market FDI acquisitions. International Business Review, 23(5), 931-941.

Ernst, H., Kahle, H. N., Dubiel, A., Prabhu, J., \& Subramaniam, M. (2015). The Antecedents and Consequences of Affordable Value Innovations for Emerging Markets. Journal of Product Innovation Management, 32(1), 65-79.

Ghauri, P. N., \& Santangelo, G. D. (2012). Multinationals and the changing rules of competition. Management International Review, 52(2), 145-154.

Ghauri, P. Hadjikhani, A. \& Elg, U. (2015). The Three Pillars: Business, State and Society: MNCs in Emerging Markets" In Business, Society and Politics. Published online: 09 Mar 2015; 3-16. http://dx.doi.org/10.1108/S1876-066X(2012)0000028008

Godey, B., Pederzoli, D., Aiello, G., Donvito, R., Chan, P., Oh, H., ... \& Weitz, B. (2012). Brand and country-of-origin effect on consumers' decision to purchase luxury products. Journal of Business Research, 65(10), 1461-1470.

Goerzen, A., \& Beamish, P. W. (2003). Geographic scope and multinational enterprise performance. Strategic Management Journal, 24(13), 1289-1306.

Hoenen, A. K., \& Kostova, T. (2014). Utilizing the broader agency perspective for studying headquarters-subsidiary relations in multinational companies. Journal of International Business Studies, 46(1), 104-113.

Hofstede, G. (1980). Culture's Consequences: International differences in work-related values. Newbury Park, CA: Sage Publications.

Hofstede, G. (2001). Cultures and Organizations: Software of Mind. 2nd ed. New York: McGraw Hill Companies, Inc.

Holden, N. (2002). Cross-cultural management: A knowledge management perspective. Pearson education.

House, R. J., Hanges, P. J., Javidan, M., Dorfman, P. W., \& Gupta, V. (2004). Culture, leadership, and organizations: The GLOBE study of 62 societies. Thousand Oaks, CA: Sage Publications.

Hua Li, J., Ran Chang, X., Lin, L., \& Ya Ma, L. (2014). Meta-analytic comparison on the influencing factors of knowledge transfer in different cultural contexts. Journal of Knowledge Management, 18(2), 278-306.

Javidan, M., House, R. J., Dorfman, P. W., Hanges, P. J., \& De Luque, M. S. (2006). Conceptualizing and measuring cultures and their consequences: a comparative review of GLOBE's and Hofstede's approaches. Journal of International Business Studies, 37(6), 897914. 
Johnson, J., \& Tellis, G. J. (2008). Drivers of success for market entry into China and India. Journal of Marketing, 72(3), 1-13.

Khanna, T., \& Palepu, K. (2013). Winning in emerging markets: A road map for strategy and execution. Hard, MA: Harvard Business Press.

Khwaja, A. I., \& Mian, A. (2005). Unchecked intermediaries: Price manipulation in an emerging stock market. Journal of Financial Economics, 78(1), 203-241.

Kuznetsov, A., McDonald, F., \& Kuznetsova, O. (2000). Entrepreneurial qualities: A case from Russia. Journal of Small Business Management, 38(1), 101-119.

Lai, C., Singh, B.; Alshwer, A.A. \& Shaffer, M.A. (2014). Building and Leveraging Interpersonal Trust Within and Across MNE Subsidiaries: A Social Exchange Perspective. Journal of International Management, 20(3), 312-326.

Lane, P. J., Salk, J. E., \& Lyles, M. A. (2001). Absorptive capacity, learning, and performance in international joint ventures. Strategic management journal, 22(12), 1139-1161.

Lucas, L.M. (2006). The role of culture on knowledge transfer: the case of the multinational corporation. The Learning Organization, 13(2/3), 257

Lockett, A., \& Wright, M. (2005). Resources, capabilities, risk capital and the creation of university spin-out companies. Research policy, 34(7), 1043-1057.

Lucas, L. M. (2006). The role of culture on knowledge transfer: the case of the multinational corporation. The Learning Organization, 13(3), 257-275.

Michailova, S., \& Mustaffa, Z. (2012). Subsidiary knowledge flows in multinational corporations: Research accomplishments, gaps, and opportunities. Journal of World Business, 47(3), 383-396.

Michailova, S., \& Hutchings, K. (2006). National cultural influences on knowledge sharing: A comparison of China and Russia. Journal of Management Studies, 43(3), 383-405.

Minbaeva, D., Pedersen, T., Björkman, I., Fey, C. F., \& Park, H. J. (2014). MNC knowledge transfer, subsidiary absorptive capacity and HRM. Journal of International Business Studies, $45(1), 38-51$.

Monteiro, L. F., Arvidsson, N., \& Birkinshaw, J. (2008). Knowledge flows within multinational corporations: Explaining subsidiary isolation and its performance implications. Organization Science, 19(1), 90-107.

Lai, M. F., \& Lee, G. G. (2007). Risk-avoiding cultures toward achievement of knowledge sharing. Business Process Management Journal, 13(4), 522-537.

Mudambi, R., Piscitello, L., \& Rabbiosi, L. (2014). Reverse knowledge transfer in MNEs: subsidiary innovativeness and entry modes. Long Range Planning, 47(1), 49-63. 
Mueller, J. (2012). Knowledge sharing between project teams and its cultural antecedents. Journal of Knowledge Management, 16(3), 435-447.

Newman, K. L. (2000). Organizational transformation during institutional upheaval. Academy of Management Review, 25(3), 602-619.

Nguyen, N. T. D., Takanashi, C., \& Aoyama, A. (2012). Can efficient technology transfer be achieved through a hybrid corporate culture? A study on Japanese Manufacturing subsidiaries in Vietnam. International Journal of Business and Management 7(7), 24-39.

Paik, Y., \& Choi, D. Y. (2005). The shortcomings of a standardized global knowledge management system: The case study of Accenture. The Academy of Management Executive, 19(2), 81-84.

Pearce, R., \& Papanastassiou, M. (2006). To 'almost see the world': Hierarchy and strategy in Hymer's view of the multinational. International Business Review, 15(2), 151-165.

Rabbiosi, L. (2011). Subsidiary roles and reverse knowledge transfer: An investigation of the effects of coordination mechanisms. Journal of International Management, 17(2), 97-113.

Ronen, S., \& Shenkar, O. (2013). Mapping world cultures: Cluster formation, sources and implications. Journal of International Business Studies, 44(9), 867-897.

Qian, L. \& Sooprmanien, D. (2015). Incorporating heterogeneity to forecast the demand of new products in emerging markets: Green cars in China. Technological Forecasting \& Social Change, 91(1), 33-46.

Qin, C., Ramburuth, P., \& Wang, Y. (2008). Cultural distance and subsidiary roles in knowledge transfer in MNCs in China. Chinese Management Studies, 2(4), 260-280.

Qiu, T. (2014). Product diversification and market value of large international firms: A macroenvironmental perspective. Journal of International Marketing, 22(4), 86-107.

Rabbiosi, L., \& Santangelo, G. D. (2013). Parent company benefits from reverse knowledge transfer: The role of the liability of newness in MNEs. Journal of World Business, 48(1), 160170.

Riege, A. (2005). Three-dozen knowledge-sharing barriers managers must consider. Journal of knowledge management, 9(3), 18-35.

Rindfleisch, A., \& Moorman, C. (2003). Interfirm cooperation and customer orientation. Journal of Marketing Research, 40(4), 421-436.

Sarala, R. M., \& Vaara, E. (2010). Cultural differences, convergence, and crossvergence as explanations of knowledge transfer in international acquisitions. Journal of International Business Studies, 41(8), 1365-1390. 
Schlegelmilch, B. B., \& Chini, T. C. (2003). Knowledge transfer between marketing functions in multinational companies: a conceptual model. International Business Review, 12(2), 215232.

Shapiro, C., \& Varian, H. R. (2013). Information rules: a strategic guide to the network economy. Harvard Business Press.

Sirmon, D. G., Gove, S., \& Hitt, M. A. (2008). Resource management in dyadic competitive rivalry: The effects of resource bundling and deployment. Academy of Management Journal, 51(5), 919-935.

Schwartz, S. H. (1994). Beyond individualism/collectivism: New cultural dimensions of values. Thousand Oaks, CA: Sage Publications, Inc.

Sheth, J. N. (2011). Impact of emerging markets on marketing: Rethinking existing perspectives and practices. Journal of Marketing, 75(4), 166-182.

Tan, J., \& Peng, M. W. (2003). Organizational slack and firm performance during economic transitions: Two studies from an emerging economy. Strategic Management Journal, 24, 12491263.

Touzani, M; Fatma, S. \& Meriem, L. M. (2015). Country-of-origin and emerging countries: revisiting a complex relationship. Qualitative Market Research: An International Journal, $18(1), 48-68$.

Trompenaars, F., \& Hampden-Turner, C. (1998). Riding the waves of culture. New York, NY: McGraw-Hill.

Uhlenbruck, K.; Rodriguez, P.; Doh, J. \& Eden, L. (2006). The Impact of Corruption on Entry Strategy: Evidence from Telecommunication Projects in Emerging Economies. Organization Science, 17(3): 402.

Üstuner, T. \& Holt, D.B. (2010). Toward a theory of status consumption in less industrialized countries. Journal of Consumer Research, 37(1), 37-56.

Vaara, E., Sarala, R., Stahl, G. K., \& Björkman, I. (2012). The impact of organizational and national cultural differences on social conflict and knowledge transfer in international acquisitions. Journal of Management Studies, 49(1), 1-27.

Van Emmerik, H,; Gardner, W.L; Wendt, H. \& Fischer D. (2010). Associations of Culture and Personality With McClelland's Motives: A Cross-Cultural Study of Managers in 24 Countries. Group \& Organization Management, 35(3) 329-367.

Van Wijk, R; Jansen J. \& Lyles, M. (2008). Inter- and Intra-Oraganizational Knowledge Transfer: A Meta-Analytic Review and Assessment of its Antecedents and Consequences. Journal of Management Studies, 45(4), 830-853.

Vance, C. M., Vaiman, V., \& Andersen, T. (2009). The vital liaison role of host country nationals in MNC knowledge management. Human Resource Management, 48(4), 649-659. 
Vance, C. M., Andersen, T., Vaiman, V., \& Gale, J. (2014). A taxonomy of potential contributions of the host country national local liaison role in global knowledge management. Thunderbird International Business Review, 56(2), 173-191.

Wang, G., Jiang, X., Yuan, C. H., \& Yi, Y. Q. (2013). Managerial ties and firm performance in an emerging economy: Tests of the mediating and moderating effects. Asia Pacific Journal of Management, 30(2), 537-559.

Wei, Y. S., Samiee, S., \& Lee, R. P. (2014). The influence of organic organizational cultures, market responsiveness, and product strategy on firm performance in an emerging market. Journal of the Academy of Marketing Science, 42(1), 49-70.

Walsham, G. (2001). Knowledge Management:: The Benefits and Limitations of Computer Systems. European Management Journal, 19(6), 599-608.

White, G. O., Hemphill, T. A., Joplin, J. R., \& Marsh, L. A. (2014). Wholly owned foreign subsidiary relation-based strategies in volatile environments. International Business Review, 23(1), 303-312.

White, G. O., Boddewyn, J. J., \& Galang, R. M. N. (2015). Legal system contingencies as determinants of political tie intensity by wholly owned foreign subsidiaries: Insights from the Philippines. Journal of World Business, 50(2), 342-356.

Wilkesmann, U., Fischer, H., \& Wilkesmann, M. (2009). Cultural characteristics of knowledge transfer. Journal of Knowledge Management, 13(6), 464-477.

Xu, D., \& Meyer, K. E. (2013). Linking theory and context: 'Strategy research in emerging economies' after Wright et al. (2005). Journal of Management Studies, 50(7), 1322-1346.

Yang, S-M.; Fang, S-C.; Fang, S-R. \& Chou, C-H. (2014). Knowledge exchange and knowledge protection in interorganizational learning: The ambidexterity perspective. Industrial Marketing Management, 43(2), 346-358.

Yang, J. Y., Li, J., \& Delios, A. (2015). Will a Second Mouse Get the Cheese? Learning from Early Entrants' Failures in a Foreign Market. Organization Science, 26(3), 908-922.

Zhang, Y., Li, H., Li, Y., \& Zhou, L. A. (2010). FDI spillovers in an emerging market: the role of foreign firms' country origin diversity and domestic firms' absorptive capacity. Strategic Management Journal, 31(9), 969-989.

Zhou, K. Z., Li, J. J., Sheng, S., \& Shao, A. T. (2014). The evolving role of managerial ties and firm capabilities in an emerging economy: evidence from China. Journal of the Academy of Marketing Science, 42(6), 581-595. 